\title{
AWARENESS OF EMERGENCY CONTRACEPTION AMONG FEMALE COLLEGE STUDENTS IN CHANDIGARH, INDIA
}

\author{
SONIA PURI, VIKAS BHATIA, H. M. SWAMI, AMARJIT SINGH*, ALKA SEHGAL**,
}

AMRIT PAL KAUR

\section{ABSTRACT}

SUMMARY: Adolescents and young women are at the greatest risk of unintended pregnancy because they are unlikely to see a family planning provider before or immediately after the sexual activity. Therefore, preventing unintended pregnancy among them is the important concern. Sexually active young women are clients with special needs for contraception. They are eligible to use a variety of the available contraceptives. Introduction of emergency contraception (EC) in the recent past can help them avoid such unintended pregnancies. OBJECTIVE: To investigate the awareness of emergency contraception in female college students. STUDY DESIGN: Cross-sectional, questionnaire-based study. MATERIALS AND METHODS: This study was conducted among college-going undergraduate and graduate female students of Punjab University, Chandigarh. Systematic random sampling was used to select the respondents. RESULTS: Of the 1,017 college students included in the study, 507 (49.9\%) knew about different contraceptive methods. Maximum awareness was regarding oral contraceptive pills $(239,47.1 \%)$. O nly $74(7.3 \%)$ had knowledge about emergency contraceptive pills (ECP). Of them, 10 (14.7\%) students knew the correct time for use of ECP, and the side effects of ECP were known to $48(88.9 \%)$ respondents. CONCLUSIONS: A wareness about ECP was very low among female college students of Chandigarh, especially regarding correct timing of its use and its side effects. Appropriate awareness programs on EC are needed for them.

Key words: A wareness, contraception, emergency contraceptive pills, family planning, female students, reproductive health

Worldwide, 70,000 women aged 15-19 years! die each year of pregnancy- and childbirth-! related causes. More than 18 million young ! women give birth to a baby each year and 9 in ! 10 of them are in developing countries. Also, in !

Department of Community Medicine, Govt ! Medical !College and Hospital Chandigarh, ! ${ }^{*}$ Community Medicine, PGIMER, **Obs and Gynae,! Govt Medical College and Hospital Chandigarh, India!

\section{Correspondence:}

Sonia Puri, !

103/17 Panchkula, India. E-mail: soniagpuri@yahoo.com! developing countries about $30 \%$ women give ! birth to the first child before their $20^{\text {th }}$ birthday..$^{[1]}$ ! Around $19 \%$ of the population in India is ! constituted of adolescents, of which 90 million ! are between 15 and 19 years of age.[2]!

The rate of premarital sex has been reported! to be $17 \%$ among young females and $33 \%$ ! among young workers in the typical north ! Indian population respondents. Sexarche (age! of first coitus) is happening earlier nowadays, ! resulting in younger adolescents engaging ! 
in sexual intercourse. The average age for! has also been reported as a highly successful ! first sexual encounter in India is 17.4 years ! for boys and 18.2 years for girls. ${ }^{[3]}$ However, majority of college students lack awareness of ! the harms of unsafe sexual encounters. Most of them resort to quacks or untrained doctors ! for abortion when they get pregnant, leading to ! unnecessary morbidity and mortality.

Women in the younger age group are twice ! as likely to be affected by complications related to childbirth compared to other age ! groups. ${ }^{[4]}$ ! Making young women aware about EC (emergency contraception) may help to ! prevent unwanted pregnancies and promote safe sex. ${ }^{[5]}$ Emergency contraception is useful ! for women who have had unprotected sexual ! intercourse, contraceptive failure or for those ! who are inconsistent in contraceptive usage and victims of sexual assault. Taken after! an act of unprotected sex, it could potentially avert many of the millions of unintended pregnancies. Emergency contraceptive pills (ECP) are also known as the morning after pill,' 'interception,' 'postcoital contraception' or 'vacation pill.' It consists of high doses of the same hormones used in oral contraceptive pills. ${ }^{[6]}$ The ECP are effective only if used within ! 72-120 h of unprotected sex. Emergency contraception includes use of combination pill (oestrogen and progesterone) or progestin-only ! oral contraceptives - danazol, Yuzpe regimen (ethinyl estradiol $50 \mu \mathrm{g}$ and levonorgestrel ! $0.5 \mathrm{mg}$ ), mifepristone, centchroman, anti-! estrogens, anti-progestogens and progestogens ! - or insertion of IUD. ${ }^{[7]}$ Out of the ECP, Yuzpe regimen that came into being in 1972 , remained ! popular for a long time until the advent of mifepristone (anti-progestin RU-486). Insertion! of IUD within 7 days of unprotected intercourse ! has also been reported as a highly successful !
method of postcoital emergency contraception..$^{[8]}$ ! It can be left in place even for 12 years for very ! effective contraception or it can be removed after ! the next menstrual period. ${ }^{[0] !}$

Although the hormonal emergency contraceptive ! pills have been technically available since! 1960s through off-label use of OCs (oral ! contraceptive pills) in most countries around the ! world, they still remain a relatively unknown and ! underused method. ${ }^{[10]}$ The hormonal emergency ! contraception concept was introduced in India ! in 2000. Now even Government supply of ECP ! is available. In 2003, emergency contraception! pill was introduced in health centers and! hospitals by the name of EC pill in India. It has ! levonorgestrel (0.75). Two pills are to be taken ! - first, within 72-120 h of unprotected sexual ! intercourse; and another, after $12 \mathrm{~h}$ of taking ! the ffirst pill. Current recommendation states ! that two pills can be taken together also. EC pill ! is considered superior over the previous Yuzpe! method because of its having more advantages ! and minimal side effects.

In India, studies on EC have been done among ! adult married women. ${ }^{[11]}$ However, level of ! awareness among the student population about ! EC has not been adequately investigated. The! present study was undertaken to ascertain the ! awareness among female college students of ! Chandigarh about contraceptive methods and ! EC.

\section{MATERIALS AND METHODS}

\section{Study site}

Chandigarh is one of the modern cities in India ! with an area of $114 \mathrm{sq}$. km, population of about !
1 million and a literacy rate of $81.6 \%$. Presence ! of large number of good educational institutions ! has drawn a large number of youth to the city. Chandigarh has 19 colleges, 1 university and ! 185 schools in the government and private ! sector.

\section{Participants}

The study was conducted between September ! 2004 and October 2005 among undergraduate ! and graduate female students of colleges and ! various departments of Punjab University, ! Chandigarh. Out of the total 19 colleges in the city, 11 colleges and few departments of the ! university consented to the study. Systematic ! random selection of 100-150 subjects was done ! from various disciplines of each participating ! college. The sampling interval was chosen! depending on the total number of eligible ! female students in each college. The disciplines! included Arts, Science, Home Science, Crafts, ! Engineering, Commerce, Literature and Law. ! The students of Health Sciences were not ! included as they were expected to know ! about EC. The main focus of the study was on nonmedical students.

$$
0
$$

A questionnaire was developed and pre-tested in ! a group of 10 students of a neighboring college. ! Language and sequence of questions were changed accordingly. The revised questionnaire! was pilot tested in a group of 20 students again ! to test the feasibility of the study.

For the main survey, first a list of students of each discipline in the selected colleges ! was made. Systematic random sampling ! was used to select 100-150 female students from each discipline. No form of identification! was required of the respondents. Anonymity ! and confidentiality of the questionnaire was ! ensured.

\section{Study material}

A self-administered questionnaire was used in ! which demographic information regarding age, ! religion, academic interests, marital status was ! included. Basic awareness among the students ! about emergency contraceptive methods ! (emergency contraceptive pills and IUD) was! evaluated. Information on ECP was taken in ! detail, like its availability; side effects; method of ! use, with special focus on the time frame, i.e., ! after how much time of an unprotected sexual ! encounter are they effective.

a

Questions were also asked about the effect! of emergency contraceptive pills on fertility, ! usage in married women or rape victims and ! about contraceptive methods in general. The ! questionnaires were distributed on the spot ! to the students. The students were supposed! to complete them during the class time. Only ! female students were present while completing! the questionnaires, and no male students were ! allowed in the class. One hour was given for! completion of questionnaire while the female ! investigator was present there to answer any ! queries. The questionnaires were collected after ! $1 \mathrm{~h}$ of distribution.

\section{Consent}

Before initiating the study in these colleges, ! principals of the concerned college were! informed about the nature and purpose of study. ! A written informed consent was obtained from ! the participants by the medical social worker. The consent form explained the purpose of ! the study. After collection of data from college ! students, educational sessions were held, in ! 


\section{Statistical analysis}

In analyzing the data, we used simple proportions and percentages. EPI info version! 6.0 was used for analysis.

\section{RESULTS}

\section{Description of study population}

Overall, 1,217!female students were enrolled! in the study, of which $131(10.8 \%)$ refused! to participate. Sixty-nine (5.7\%) did not give ! complete information. Hence, 1,017 students ! were Ifinally included in the study. Mean age ! of the respondents was 18.3 years $(S D=2.4$ ! years). Although the range was 17-25 years, ! only $2.5 \%$ were $>25$ years of age. Of the total ! study subjects, 457 (44.9\%) were Hindu, ! followed by $398(39.1 \%)$ Sikhs. The numbers! of students who were Muslim, Christian and ! 'Others' were 6,5 and $4.7 \%$ respectively. ! Majority $(67 \%)$ of the girl students were day ! scholars. The rest were boarders $(20.1 \%)$ or! staying in private accommodation as paying ! guests (12.9\%). Among the 1,017 students, ! $2.2 \%$ were married.

\section{Awareness regarding various} contraceptive methods

Of the 1,017 respondents, 507 (49.9\%) ! knew about different contraceptive methods. Maximum awareness was regarding oral! contraceptive pills $(47.1 \%)$, followed by condom (49.7\%) and IUD (intrauterine device) ! $(23.1 \%)$. When asked from where these ! could be obtained, $9.8 \%$ of the students ! reported hospitals as the main source, $89.3 \%$ ! reported that these could be obtained from ! health centers and $69.3 \%$ said the main ! source was the chemist's shop. More than half ! (57.8\%) female students had seen at least one ! contraceptive. Oral contraceptive pills had been ! seen by $73.3 \%$, condoms by $32.8 \%$ and IUD by ! $4.8 \%$ of the students [Table 1 ].

\section{Awareness of emergency contraception}

Only $7.3 \%$ respondents were aware of EC ! methods. Among 74 students who were aware! of EC, the majority $(73 \%)$ knew that they ! were in the form of pills. Eleven (14.9\%) were ! aware of IUD to be used as an emergency ! contraceptive method, whereas 9 (12.2\%)! reported awareness about other untested home ! remedies like jumping backwards, blowing ! nose, etc.

Most students were unaware of the exact time! frame in which these pills had to be used. ! Only $14.7 \%$ knew that a woman should take ! the ECP within $72 \mathrm{~h}$ of unprotected sex. While ! many $(47 \%)$ students felt that it had to be used ! immediately after unprotected sex, 26 (38.2\%)!

Table 1: Awareness of contraceptive methods in female students of Chandigarh

\begin{tabular}{|c|c|c|}
\hline & Yes (\%) & No (\%) \\
\hline $\begin{array}{l}\text { Awareness of contraception! } \\
(n=1017) ! \\
\text { Aware about different methods }\end{array}$ & $507(49.9) !$ & $510(50.1) !$ \\
\hline of contraception* ${ }^{*}(n=507)$ & & \\
\hline Condoms & $252(49.7) !$ & \\
\hline IUD & $117(23.1)$ & \\
\hline Oral contraceptive pills! & $239(47.1) !$ & \\
\hline Tubectomy & $7(1.4)$ & \\
\hline Vasectomy & $5(1.0) !$ & \\
\hline $\begin{array}{l}\text { Awareness about place of ! } \\
\text { availability of various! }\end{array}$ & $!$ & \\
\hline Contraceptives*! & $496(97.8) !$ & $11(2.2) !$ \\
\hline $\begin{array}{l}\text { Hospitals }(n=496) ! \\
\text { Health centers }(n=496) !\end{array}$ & $\begin{array}{r}49(9.8) ! \\
443(89.3)\end{array}$ & \\
\hline $\begin{array}{l}\text { Over the counter (chemists) ! } \\
(\mathrm{n}=496)\end{array}$ & $332(66.9) !$ & \\
\hline Ever seen any contraceptive ${ }^{*}$ ! & $293(57.8) !$ & $214(42.2) !$ \\
\hline Condom $(n=293) !$ & $96(32.8) !$ & \\
\hline Oral contraceptive pills ( $n=293$ ) & 215 (73.4)! & \\
\hline Cu-T $(n=293) !$ & $14(4.8) !$ & \\
\hline
\end{tabular}

thought that the pills had to be used within $12 \mathrm{~h}$ ! of unprotected sex and 6 (8.1\%) did not know ! about this aspect.

Of the 54 girls who knew about ECP, 6 (11.1\%)! did not know about the side effects. Majority ! (97.9\%) thought that taking ECP might cause ! hormonal changes in their bodies. Forty ! (83.3\%) respondents answered 'nausea' and ! 'vomiting' as side effects. Headache as a side ! effect of ECP was reported by 37 (77.7\%) girls ! and dizziness by 29 (60.4\%).

!

Some $(32.4 \%)$ girls said that EC could be ! used in case of rape. Thirty-two (43.2\%) girls ! acknowledged its usage by married couples. Ten ! $(13.5 \%)$ girls believed infertility to be a potential ! risk of ECP, whereas a majority $64(86.5 \%)$ felt ! that it had no effect on fertility [Table 2].

\section{DISCUSSION}

Early sexual activity in young women is fraught ! with a relatively higher chance of unprotected! sexual intercourse. This is because of the nature of their relationship with their partners, ! which may involve difficulties in negotiating ! safe sex as well as problems in having a steady ! relationship. Hence when young women choose ! to have sexual intercourse, multiple strategies ! are necessary to encourage them to avoid! unintended pregnancies. One such strategy is to increase awareness of EC among them.

In India, where rates of unplanned pregnancies ! and illegal abortions are high, it is estimated that $78 \%$ pregnancies are unplanned and $25 \%$ are definitely unwanted, despite a 'National Family ! Welfare Programme' and widespread efforts ! by the government. ${ }^{[12]}$ The number of unsafe ! abortions has also been increasing despite ! legalization of abortion in India through MTP ! Act in 1972. However, morbidity associated with ! abortion is preventable to a great extent through ! use of suitable contraception. Introduction of EC through government supply in the new ! millennium has a potential to significantly! change the scenario by empowering the young ! females in India.

The hormonal EC pills reduce the risk of ! pregnancy by up to $95 \%$, and EC IUD insertion ! reduces such risk by $99.9 \%{ }^{[13]}$ Young women! can safely use hormonal EC. In a study! designed to evaluate the safety of EC in ! adolescents in USA $(n=52)$, EC pills were! found to be well tolerated by them. They! returned to their regular menstrual cycle at! returned to their re

Table 2: Awareness of emergency contraception in female students of Chandigarh \begin{tabular}{lll} 
& Yes (\%) & No (\%) \\
\hline Awareness of EC $(\mathrm{n}=1017) !$ & $74(7.3) ! 943(92.7) !$
\end{tabular} Awareness of EC $(n=1017)$ Aware of diff
$E C(n=74) !$ Emergency contraceptive Pills! 54 (73.0)! IUD $\quad 54(73.0) !$ Other methods ! Awareness about time limit for! taking EC after unprotected! intercourse $(n=74)$ ! Immediately after $(\mathrm{n}=68)$ ! Upto $12 \mathrm{hr}$ later $(\mathrm{n}=68)$ ! Knowledge about side KCP* $(n=54) !$ Vomiting $(n=48)$ ! Vomiting $(n=48)$ !
Headache $(n=48) !$ Hormonal changes $(n=48)$ ! Dizziness $(n=48)$ ! Perceived usefulness of EC for ! married women $(n=74)$ ! Perceived effectiveness in rape ! victims $(\mathrm{n}=74)$ ! Awareness of availability of Hospital $(n=72)$ Health centre $(\mathrm{n}=72)$ ! 9 (12.2)!

$68(91.9) ! \quad 6(8.1) !$ 32 (47.0.)! $26(38.2)$ ! $48(88.9) ! 6(11.1) !$

40 (83.3) $37(77.1) !$ $47(97.9) !$ $29(60.4)$ $32(43.2) ! 42(56.8) !$ 24 (32.4)! 52 (70.3)! $\begin{array}{ll}\text { Over the Counter (chemists) }(\mathrm{n}=72) ! & 25(34.7) \\ 32 & (44.4)\end{array}$ Knowledge of adverse effect on fertility $(n=74)$ ! $10(13.5) ! 64(86.5)$ ${ }^{\star}$ More than 1 option was selected by some respondents! 
the same rate as adult women taking ECP. ${ }^{[14]}$ ! ECP should not be used in women who are pregnant, not because they are thought to ! be harmful but because they are ineffective at terminating established pregnancies. ${ }^{[15]}$ ! Emergency contraception decreases the risk of ectopic pregnancy. ${ }^{[15]}$ However, it does not prevent the spread of sexually transmitted infections, including HIV. Also for women suffering from STDs (sexually transmitted diseases), EC pills are likely to be a safer ! choice than IUD insertion. ${ }^{[16] !}$ !

It is evident from the present study that the participants' awareness pertaining to ! various methods of contraception was more as compared to their knowledge regarding EC, which was rather insufficient $(7.3 \%)$. In Ghana also, Frank et al. found the awareness ! regarding EC to be $11.9 \%$ among university students. ${ }^{[17]}$ However, the awareness level reported in our study is low as compared to the situation in developed countries. Glei et al. studied a 'general practice'-based ! population of 1,290 women aged 17-50 years in California, of whom $28 \%$ had heard of ECP. ${ }^{[18,19]}$ Graham found the awareness level about EC in teenagers in Southeast Scotland to be $93.0 \%{ }^{[20]}$ A study in USA revealed that ! only $23 \%$ young women knew about ECP. ${ }^{[21]}$ ! Similar findings from a study done by Cynthia ${ }^{[22]}$ ! showed the awareness to be $95 \%$ in Princeton University students. Such differences in the awareness levels in different countries with respect to contraception may be due to their ! cultural differences and government policies. !

Our study highlights that even among the students who were aware of ECP, knowledge ! regarding correct time for using ECP was inadequate (14.7\%). George et al. ${ }^{[23]}$ also ! reported that only $13.6 \%$ students were aware of ! this aspect. In Western countries, an awareness ! level of $9-29 \%$ about usage of ECP has been ! reported by various authors. ${ }^{[24-27]}$ Delbanco et al. ${ }^{[27]}$ reported that out of 423 teenagers who had! heard of EC pills, one-third (32\%) did not know ! that they needed to get them from a physician, ! and three-quarters $(74 \%)$ underestimated the ! time regarding how long after sexual intercourse ! could they initiate the regimen. Only $9 \%$ knew ! that EC pills could be used up to $72 \mathrm{~h}$ after ! unprotected sex.

$$
\text { (2) }
$$

Combination hormone EC pills induce nausea! in $30-50 \%$ of women and vomiting in $15-25 \%$ ! of women. ${ }^{[28]}$ In our study, more than three-! quarters of the respondents knew about nausea! being one of the side effects (83.3\%). Many of ! our respondents feared that hormonal changes! could be induced in the body owing to intake ! of EC pills that had higher doses of hormones, ! as is the case in some brands. Other side! effects enumerated by more than half of our ! respondents were dizziness and headache. ! Many other studies done in young women have! also reported these side effects along with few ! more like breast tenderness, fatigue, irregular ! bleeding and abdominal pain. ${ }^{[29]}$ !

Emergency contraception is the only method ! that can be used to prevent pregnancy after ! unprotected sex or contraceptive accident. ECP ! are needed because no method is $100 \%$ safe ! or reliable and few people use their methods ! perfectly each time they have sex. Emergency! contraception is undoubtedly useful in sexual ! assault cases. ${ }^{[30]}$ In our study, one-third of the ! participants answered that it is useful in victims! of sexual assault. However, one-tenth of them ! felt that EC had adverse effect on fertility.

ECP provide women with a second chance at prevention in cases of unanticipated sexual ! activity. ${ }^{[31]}$ In India, EC pills are now available ! over the counter in the private sector as well ! as through government supply. Anybody! can procure these, even without the doctor's! prescription. In the present study, almost half of ! the girls were aware that these could be obtained! over the counter, whereas the rest thought that ! these could be obtained from the hospitals or ! health centers. This development is going to ! revolutionize the contraceptive choice available ! to the Indian females, particularly the younger! ones. However, as our study result indicates, ! there is a strong and urgent need to educate the ! young females about correct use of EC. !

It may be argued that promotion of awareness ! about EC may encourage premarital sex/sexual! risky behavior. There is no scientific evidence, ! however, to substantiate any of these arguments. ! A wealth of research clearly demonstrates! that improving the availability of EC does ! not increase any form of 'sexual risk'-taking ! behavior. ${ }^{[32-34]}$ Rather, it was found that use of EC ! might be the stimulus that brings young women! into contact with health care providers, thus providing opportunities for counseling in matters ! of responsible sexual behavior; contraception; ! and prevention of sexually transmitted diseases, ! including HIV/AIDS.

One of the limitations of our study was that it ! was based on only young women pursuing ! higher studies. Hence our study may not! be truly representative of young females of Chandigarh. In fact, this was planned just as ! an exploratory study to evaluate the awareness ! and inquisitiveness of the female students! and their response to the questionnaire. ! Further studies are being planned on these ! aspects. Therefore, deeper aspects of regular! contraceptives and ECP were not covered! - e.g., disadvantages of Ecp like not providing ! protection against STDs and HIV, thrombotic ! problems, extra-abdominal pregnancy, irregular! menstruation, consequences on using it ! frequently, contraindications of its usage, ! efficacy of intrauterine devices in comparison! to Yuzpe regimen, etc. Information on injectable ! and implantable hormonal contraceptives was! not sought as only $2.2 \%$ of students were ! married. However, all these aspects were ! covered in the educational sessions conducted! after collection of data from girls.

is

The strength of our study lies in the fact that ! it focused on young females rather than only! on adult married females. ${ }^{[11]}$ Many studies ! have been done on married females but not! on college students, who also are important ! candidates for awareness generation with ! respect to EC.

The authors feel that health professionals can ! play a larger role in informing young women! about EC. Many young women in our study ! reported that they relied on health professionals ! for information on birth control. This suggests ! that strategies on promotion of EC should focus ! on health professionals too.

\section{CONCLUSIONS}

EC is an effective means of preventing ! unwanted pregnancies, but unfortunately ! majority of the college-going female students ! are either unaware or poorly informed of 
it. More efforts should be exerted towards improving the awareness of, and access to, emergency methods and enhancing their usage by potential users.

\section{REFERENCES}

1. !Kanojia K, Nirbhavane NC, Toddywala VS. ! Dynamics contraceptive practice amongst urban ! Indian Women. Int J Gynae Obst 2002:197-8.

2. ! Gy Bartfai. Editorial emergency oral contraception ! in global perspective. In J Gynae Obs 2002:191-! 8.

3. !Sharma R. More than a quarter of India's ! youngsters have premarital sex. BMJ! 2001;322:575-9.

4. !Harper C, Ellertson C. The emergency contraceptive pill: A survey of knowledge and I attitudes among students at Princeton University. ! Am J Obst Gynecol 1995;173:1438-45.

5.! Harper C, Ellertson C. Knowledge and perceptions! of the emergency contraceptive pill among a ! college-age population: A qualitative approach. Fam Plann Perspect 1995;27:149-54.

6. !Delbanco S, Mauldon T. Little knowledge and limited practice: Emergency contraceptive pills, ! the public and the obstetrician-Gynecologist. Am ! J Obst Gynaecol 1997;89:1006-11.

7. ! Glei DA. Measuring contraceptive use patterns ! among teenage and adult women. Fam Plann ! Perspect 1999:31:73-80.

8. !WHO. Selected practice recommendations for contraceptive use, $2^{\text {nd }}$ ed. World health ! Organization: Geneva, Switzerland; 2004. Available from: http:/www.who.int/reproductive-! health/publications/spr/spr.pdf.

9. ! Hatcher, Robert A. A Pocket Guide to Managing ! Contraception, 2005-2007 Edition. Tiger, GA: ! Bridging the Gap Foundation!

10. ALL-(American life league). "Birth control: ! Emergency Contraception: The morning after pill."! 1997. [Last accessed on 2000 Mar 3]. Available ! from: http://www.all.org/issues/bc05.htm.
11. Takkar N, Goel P, Saha PK. Contraceptive practices! and awareness of emergency contraception ! in educated working women. Indian J Med Sci ! 2005;59:143-7.

12. Emergency Contraception. Training Manual for ! health care Providers. WHO collaborative centre ! for Research in Human Reproduction, Dept Of Obs ! and Gynae: AllMS, New Delhi; 2000. p. 17-8.

13. Harper $C$, Cynthia C. Tolerabillity of levonorgesterol! emergency contraceptions in adolescents. Am J Obstet Gynaecol 2004;173:1158-63.

14. Rowlands S, Devalia H, Lawrenson R. Repeated ! use of hormonal contraception by younger women ! in the UK. Br J Fam Plann 2000;26:138-43.

15. Raine T, Harper C, Leon K. Emergency ! contraception: Advanced provision in a young, ! high risk clinic population. Obstet Gynaecol ! 2000;96:1-7.

16. Grimes DA, Raymond EG. Emergency ! Contraception over the counter: The medical and! legal imperatives. Obstet Gynaecol 2001;98:151-! 5.

17. Baiden F, Elizabeth A. Perception of university ! students in Ghana about emergency contraception. ! Contraception 2002;4:23-6.

18. Glei DA. Measuring contraceptive use patterns ! among teenage and adult women. Fam Plann ! Perspect 1999;31:73-80.

19. Smith B, Gurney E, Aboulcla L. Emergency ! contraception: A survey of women's knowledge and ! attitudes. Br J Obstet Gynaecol 1996;103:1109-! 16.

20. Graham A, Green L, Glasier A. Teenager's ! knowledge of emergency contraception.! Questionnaire survey in southeast Scotland.! BMJ 1996;312:1567-9.

21. Belzer M, Yoshida E, Tejirian T. Advanced supply ! of emergency contraception for adolescent ! mothers increased utilization without reducing ! condom or primary contraception use. J Adolesc ! Health 2003;32:122-3.

22. Cynthia C, Harper MA, Ellertson K. The emergency ! contraceptive Pill -A survey of Knowledge and !
Attitudes among students at Princeton University ! Am J Obst Gynaecol 1995;173:1438-45.

23. George J, Turner J, Cooke E, Hennessey E, ! Savage W, Julian $\mathrm{P}$, et al. Women's knowledge ! of emergency contraception. Br J Gen Pract ! 1994:44:451-4.

24. Pearson V, Owen MR, Phillips DR, Periera G Ray ! DJ. Pregnant teenagers' knowledge of use of ! emergency contraception. BMJ 1995;40:326-30.

25. Crosier A. Women's knowledge and awareness ! of emergency contraception. Br J Fam Plann ! 1996;22:87-90.

26. Ronald A, Chez MD. Emergency Oral ! Contraception. Int J Obstet Gynaecol 2002;78:191-! 8.

27. Delbanco S. Repeated usage of emergency ! contraception by younger women in USA. Arch ! Pediatr Adolesc 1998;727-33.

28. Harper MA, Cynthia C. The effect of increased access to emergency contraception among young! adolescents. Obstet Gynaecol 2005;106:483-91.

29. Knowles, Jon, Ringel M. All about birth control. !
Three Rivers Press: New York; 1998.

30. Gold MA, Schein A, Coupey SM. Emergency ! contraception: A national survey of adolescent ! health experts. Fam Plann Perspect 1997;29:15-! 24.

31. Gold M. The effects of advance provision of ! emergency contraception on adolescent women's! sexual and contraceptive behaviors. J Pedia! Adolesc Gynaecol 2004;17:87-96.

32. Lo !SS, !Fan SY. Effect of advanced provision of emergency contraception on women's! behavior: A randomized control trial. Hum Reprod! 2004;19:2404-10

33. Jackson RA, Bimla E. Advance supply of ! emergency contraception: Effect on use and usual ! contraception- randomized control trial. Obstet ! Gynaecol 2003;102:8-16

34. Glasier A, Baird D. The effects of self administering! emergency contraception. N Engl J Med ! 1998;399:1-4.

Source of Support: Nil, Conflict of Interest: None declared.

\section{Author Help: Reference checking facility}

The manuscript system (www.journalonweb.com) allows the authors to check and verify the accuracy and style of references. The tool checks the references with PubM ed as per a predefined style. Authors are encouraged to use this facility before submitting articles to the journal.

- The style as well as bibliographic elements should be $100 \%$ accurate to get the references verified from the system. A single spelling error or addition of issue number / month of publication will lead to error to verifying the reference.

- Example of a correct style

Sheahan P, O'leary G, Lee G, Fitzgibbon J . Cystic cervical metastases: Incidence and diagnosis using fine needle aspiration biopsy. Otolaryngol Head Neck Surg 2002;127:294-8.

Only the references from journals indexed in PubM ed w ould be checked.

- $\quad$ Only the references from journals indexed in PubMed would

- $\quad$ Enter each reference in new line, without a seria maximum 15 reference at time.

- $\quad$ Add up to a maximum 15 reference at time.

to the correct article in PubM ed will be given.

Dits and punctuations, it will be shown as CORRECT and a link If any of the bibliographic elements are missing, incorrect or extra 